\title{
A comparison of the gamma index and dose volume histogram of patient for IMRT/VMAT with different QA systems
}

\author{
Yasser H. Ali ${ }^{1 *}$, Kh. El Shahat ${ }^{2}$, HosniaAbou Zeid ${ }^{3}$, and Hoda A. Ashry ${ }^{4}$
}

$1^{*}$. M.Sc. in Biophysics, Radiotherapy Department, El-galaa Hospital

2. Medical Radiation Biophysics, Faculty of Medicine, Al-Azhar University

3. Physics Department, Women Faculty for Arts, Science, and Education, Ain -Shams University

4. National Center for Radiation Research and Technology, Atomic Energy Authority

\begin{abstract}
Radiotherapy has a vital part in the treatment of prostate tumor. Three-dimensional conformal radiotherapy (3D-CRT), intensity modulated radiotherapy (IMRT) and volumetric modulated arc therapy (VMAT) techniques are currently used. In this concern, the present study is a trial to shed further light on the mean differences and to note the similarity or dissimilarity between the proposed three techniques of radiotherapy for head \& neck $(\mathrm{H} \& \mathrm{~N})$ cancer. Measurements were carried out based on two dimensional (2D) array PTW and portal dosimetry in patient with head and neck canceras tool for evaluation. Specifically, the aim of the first part was to demonstrate that quality assurance (QA) tool for IMRT and its passing rate criteria might not expect dose errors in patient. This study examines the effect of systematic positional multileaf collimator (MLC) bank errorson gamma $(\Gamma)$ examination results used for QA of treatment technique and to assess the result of dose changes presented in dynamic multi-leaf collimator (DMLC) modeling and delivery methods on metrics for IMRT.
\end{abstract}

Twenty head and neck IMRT plans were selected for current study using the same group of dose-volume constraints. Treatment plans were created using 3D-CRT, VMAT and IMRT techniques. Homogeneity index (HI), Conformity index (CI), max. spinal cord dose, max. brainstem dose, mean parotid dose, larynx dose, oral cavity dose, and monitor units (MUs) were compared. For every patient, a group of data analysis was done for each technique and then imported to the DVH (PTW 2D array) for processing. A measured dose volume histogram metrics (DVH) was created in QA system and note the similarity to the calculated DVH from the treatment plan. Their variations due to errors related to the treatment planning system (TPS) (its algorithm for dose calculation) in addition to beam delivery.

It is clearly shown that VMAT has a little better CI whereas the volume of small doses was higher.VMAT had lesser MUs than IMRT. 3D-CRT had the lowest common MU, CI and HI. IMRT would be preferred to VMAT in head and neck radiotherapy. Also, the current study showed even if the whole of IMRT QA had high Gamma passing rates $98.3 \pm 1.3 \%$ (96.7-99.7\%) for " $3 \% / 3 \mathrm{~mm}$ " criteria, there were located significant errors in some of the calculated clinical dose metrics. This study approves that conventional IMRT QA are not a prescient warning of errors in PTV dose and OAR dose (organs at risk). The dose QA has to allow us to expect and evaluate the relation of results of gamma test and DVH for treatment technique plan.

Keywords: IMRT, Head and Neck cancer, TPS plan evaluation, plan QA, Gamma Index and DVH.

*Corresponding author:

Email: ysrhassan71@gmail.com 


\section{Introduction}

Around $50 \%$ of the whole of tumor patients in the world get radiation therapy throughout the course of their treatment. The target of radiation therapy is to save local tumor control point and acceptable of the side effects of normal tissue for early and late lethal effects. The hazard rises with dose have been illustrated by some studies. Several studies had expressed by raising the volume of (OAR) normal tissue getting low doses, might raise the occurrence of secondary tumor. A linear relationship occurs among cancer and received dose from around $0,1 \mathrm{~Sv}$ up to round 2, $5 \mathrm{~Sv}$ [Hall W. A. et al, 2013], [Fogarty G. B. et al, 2011]. These data explain the highest quality level for our information regarding of radiation-prompt tumor. In the greatest cases, the risk estimation of second tumors in radiation therapy patients is complicated, due to there is practically not control set treated in the absence of radiation expect for cancer of head and neck.

In addition to the regular procedure conventional radiation therapy techniques used in standard radiation therapy departments and clinics, a number of specific techniques are known and used for particular procedures, be it in dose delivery or target localization. The radiotherapy techniques that currently fall into the specialized category are 3D Conformal Radiotherapy (3DCRT) as a forward planning system, Intensity Modulated Radiotherapy (IMRT) and Volumetric-Modulated Arc Therapy (VMAT) as an inverse planning system. Conformal radiotherapy conforms or shapes the prescription dose volume to the Planning Target Volume (PTV) while at the same time keeping the dose to specified (OAR) organs at risk below their tolerance dose. The conformal radiotherapy chain is based on 3-D target localization, 3-D treatment planning and 3-D dose delivery techniques. On the other hand, IMRT treatments can be delivered with the MLC operating in one of three basic modes [Zelefsky MJ et al, 2012]:

- The Segmented MLC (SMLC) mode, often referred to as the step and shoot mode (static IMRT)

- The Dynamic MLC (DMLC) mode, sometimes referred to as the sliding window mode (dynamic IMRT);

- Intensity Modulated Arc Therapy (IMAT) or Volumetric-Modulated Arc Therapy (VMAT).

Volumetric-modulated arc therapy delivers radiation by rotating the gantry of a linear accelerator through one or more arcs through the radiation continuously on. As it does so, a number of factors can be varied, these include:

i) the MLC opening shape,

ii) the fluence-output rate ("dose rate"),

iii) the gantry rotation speed and

iv) the MLC orientation

In external beam radiotherapy (EBRT), treatment had at all times aimed at managing enough dose coverage to the whole tumor target volume though protecting the encirclement normal tissues. The correlation among the planning dose (restrictions) constraints and the output dose distributions based on a number of parameters, particularly differences in the anatomic association among the cancer and critical structures.

The increasing difficulty of IMRT/VMAT treatments beside its common adoption need an powerful and comprehensive quality assurance (QA) database, both in terms of treatment 
precision of machines delivery and treatment accuracy of planning system (TPS) prediction [Nelms B. E. et al, 2011]. Therefore, dedicated pretreatment patient-specific QA procedures are required for the purpose of discovering probability of a discrepancy between the calculated dose by TPS and the delivered dose by therapy machines[ICRU-10(1), 2010].Conventional IMRT/VMAT QA is usually performed by applying the patient plan to a phantom and comparing the measured and calculated phantom dose distributions. Phantom dose distributions are first calculated by a TPS and then delivered and measured at the treatment machine. A very common method to quantitatively compare measured and calculated dose maps is the calculation of gamma index (GI).This method, first introduced by Low et al. [Low, D. A. et al, 1998] represents the minimum multidimensional distance between the measurement and calculation points in a space composed of dose and physical distance coordinates, scaled by preselected limits called acceptance criteria for distance to agreement (DTA) and dose differences (\%DD).A gamma index GI smaller than unity indicates that the measured absorbed dose agrees with the calculated one within the passing criteria. The goodness of a treatment plan is measured through the evaluation of the gamma passing rate (\%GP), which represents the percentage of dose points per plan that comply the acceptance criteria.

IMRT quality assurance (QA), as recommended by AAPM Task Group 119 [Ezzell, G. A. et al, 2009] and other studies [Low, D. A. et al, 1998], [Bailey, D. W. et al, 2011], employ the Gamma index for the measurable assessment of dose distributions. They reported that the $3 \%$ dose difference and $3 \mathrm{~mm}$ DTA criteria is most commonly used by physicists in pretreatment IMRT QA. Furthermore, GI method is limited by the fact that it only determines the number of points out of tolerance without giving any information about their spatial location. Therefore, one cannot assume that the \%GP of the entire plan corresponds to the one of the single organ.

Though, as some others had observed[Kruse, J. J. 2010], the positions and average magnitude of the errors mightdemonstrate the truth more important than the quantity of errors, e.g. a relatively larger error in the max. cord dose might not decrease the overall Gamma passing rate, because its comparatively small volume related to the volume under therapy, but its effect may not be acceptable. Recent studies [Zhen, H. et al, 2011],[Lawrence, M. et al, 2011] have demonstrated the insensitivities of plane QA dose in expecting IMRT QA errors. Therefore, to expect the errors in patient dose, IMRT QA must contain the assessment of patient anatomy associated to the clinical effect of the dose error.

\section{Materials and Methods}

The whole of patients were scanned by Open Computed Tomography (CT-simulator) with the same protocol. CT datasets of 20 patients with head and neck tumor who got radiotherapy course in our hospital were applied for this relative planning research. All patients were treated with one of the advanced techniques (IMRT). These patients included a different selection of tumor sites. To do accurate patient positioning, treatment assistance tools and fixation devices are used. These tools are immobile to the treatment couch for well reproducibility. The whole of planning computed tomography CT scans are got by using Conventional CT. Thermoplastics are used for the treatment of the head and neck regions.All patients were simulated supine using a large Aquaplast mask (Civco Medical Soutions, Kalona, IA) holding their chin in a neutral position on a GE Light Speed 16-slice CT scanner (GE Medical Systems, Milwaukee, WI) with Flat table top (GE CT) with $2.5 \mathrm{~mm}$ thickness per section were obtained from the top button of vertex to the plane of the carina. To account for 
organ motion and patient setup errors, the PTVs for dose painting are defined as follows, the gross tumor volume (GTV) enclosed to the detectible primary cancer and neck nodes $>10 \mathrm{~mm}$ in diameter with necrotic centers. The clinical target volume (CTV) was exactly described as CTV $(70 \mathrm{~Gy})=\mathrm{GTV}+5 \mathrm{~mm}$ as border of margin (the GTV plus a margin ranging anywhere from 3 to $10 \mathrm{~mm})$, CTV $(60 \mathrm{~Gy})=$ high hazard zone (subclinical disease volume plus typically 5 to $10 \mathrm{~mm}$ margin) also CTV (54 Gy): low hazard zone (subclinical disease plus 5 to $10 \mathrm{~mm}$ margin). Planning target volumes (PTV) was formed by giving a safety margin of $3-10 \mathrm{~mm}$ at all directions to CTV, situated as measured localization uncertainty, inter-user reproducibility and intra-fraction movement.For $6 \mathrm{MV}$, accounting to the beam penumbra, the beam border was set to be $5.0 \mathrm{~mm}$ from the planning target volume in the coplanar direction and $6.0 \mathrm{~mm}$ from the planning target volume for the perpendicular direction to the plane of beam direction (along the z-direction).

Normal structures including the lenses, eyes, optic nerves, pituitary gland, chiasm, mandible, brain stem, parotid glands, spinal cord, submandibular glands, oral cavity, larynx, thyroid gland and pharyngeal muscles were delineated as organs at risk on the planning CT images. A normal structures (OAR) volume was described exactly as the total patient volume without the planning target volume. The goal is to deliver the prescribed dose of 70 Gy to PTV $\mathrm{PV}_{70}$ 59.4 Gy to PTV 59.4 , and 54 Gy to PTV $_{54}$ in 33 sessions and to save the dose to the critical organs within constraints.

VMAT, IMRT in addition to 3DCRT plans were sophisticated using the Eclipse (Varian Medical System, Palo Alto, California, USA) Version 13.6 Treatment Planning System (TPS) with $6 \mathrm{MV}$ for each patient. AAA (Analytical Anisotropic Algorithm, Varian Medical System, Palo Alto, California, USA) was utilized to calculate the dose distributions. Inverse treatment plans for IMRT and VMAT were created employing the identical dose volume limitations (constraints) for the whole of plans.

In the head and neck cancer treatment plan, dose volume constraints for the target and critical organs are used in the plan optimization based on objective function [Xing L. et al, 1999]. The dose constraints were set for max. spinal cord dose, max. brainstem dose, oral cavity dose, larynx dose, mean parotid dose shown in Table (1).

Table (1): Dose constraints for target (PTV) and organ at risk (OAR)

\begin{tabular}{|c|c|c|}
\hline Region of Interest & Dosimetric Parameter & $\begin{array}{c}\text { Recommended Dose } \\
\text { Coverage (Gy) }\end{array}$ \\
\hline Targets (node level) PTV $_{70}$ & Minimum D $_{95} \%$ & 70 \\
\hline PTV & Maximum D $_{20} \%$ & 77 \\
\hline PTV & Minimum D $_{99} \%$ & 66.5 \\
\hline PTV & Maximum Dose & 80.5 \\
\hline PTV & Maximum Mean Dose & 73.5 \\
\hline Spinal Cord & Maximum Dose & 48 \\
\hline Spinal Cord & Maximum dose to $1 \mathrm{~cm}^{3}$ & 45 \\
\hline Brainstem & Maximum Dose & 54 \\
\hline
\end{tabular}




\begin{tabular}{|c|c|c|}
\hline Brainstem & Maximum dose to $1 \mathrm{~cm}^{3}$ & 50 \\
\hline Optic Chiasm & Maximum Dose & 50 \\
\hline Right or Left Optic Nerve & Maximum Dose & 50 \\
\hline Oral Cavity & Maximum Mean Dose & 40 \\
\hline Brain & Maximum Dose & 60 \\
\hline Brachial Plexus & Maximum Dose & 63 \\
\hline Right or Left Parotid & Maximum Mean Dose & 26 \\
\hline Right or Left Parotid & Maximum D $_{50} \%$ & 30 \\
\hline Combined Parotids & Maximum D $_{20} \mathrm{~cm}^{3}$ & 20 \\
\hline Pharyngeal Constrictors & Maximum Mean Dose & 50 \\
\hline Mandible & Maximum dose to $1 \mathrm{~cm}^{3}$ & 70 \\
\hline Mandible within the PTV & Maximum dose to $1 \mathrm{~cm}^{3}$ & 75 \\
\hline Larynx & Maximum D & \\
\hline Larynx & 50 \\
\hline Esophagus & Maximum Mean Dose & 45 \\
\hline Lips & Maximum Mean Dose & 45 \\
\hline Orbit & Maximum Dose & 30 \\
\hline Lens & Maximum Dose & 45 \\
\hline Lacrimal Glands & Maximum Dose & 5 \\
\hline Anterior Chamber & Maximum Dose & 30 \\
\hline Acoustic Structures (Nerve, & Maximum Dose & 25 \\
\hline Cochlea, Inner or Middle Ear) & Maximum Dose & 45 \\
\hline
\end{tabular}

\subsection{Plan Generating (3D CRT, IMRT, VMAT)}

Producing a good dose distribution with fewer numbers of total MUs and segments fundamentally requires an appropriate selection of number of beams and their angles.

\section{1- 3DCRT treatment techniques for 3D-CRT radiation therapy planning protocol:}

After contouring all normal structure and critical organ, the traditional treatment plan for HN irradiation consists of opposed lateral cranial fields or 2 posterior oblique fields. To avoid deviation of beam into the spine fields, the couch is shifted and the collimator would be also rotated to agree the divergence of the spine field. The cranial and spine fields use an isocentric arrangement with a point of normalization situated mid-plane in the PTV. For this study, the original 3D-CRT plans were renormalized to a prescription dose of 70Gy. The prescribed dose was normalized to $100 \%$ at the isocenter, and $95 \%$ isodose surface covered the PTV. Figure (1) shows typical dose distribution 3D-CRT fields. 


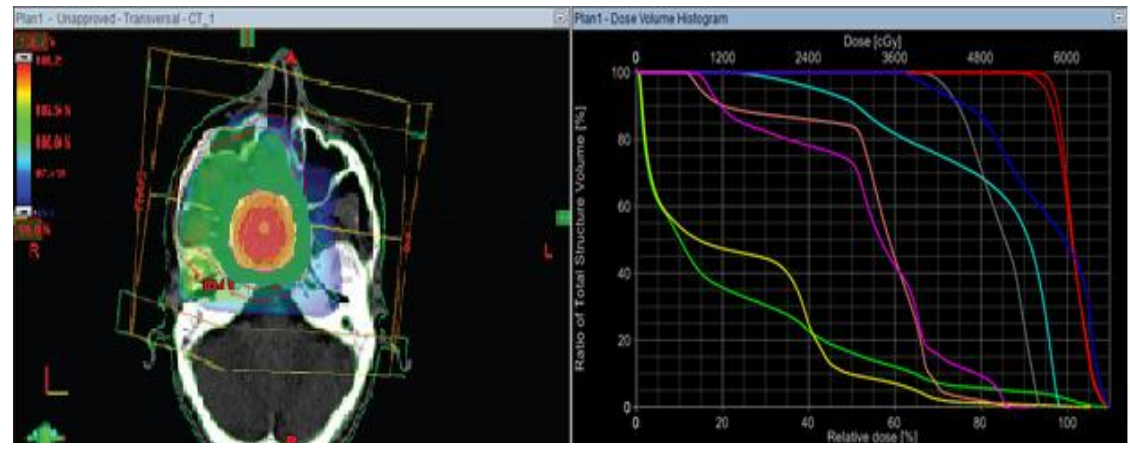

Figure (1): CT image of the axial view and DVH for HN plan with 3DCRT (conformal plan)

\section{2- IMRT treatment techniques for IMRT radiation therapy planning protocol:}

Before optimizing the entire $\mathrm{HN}$ treatment volume, the dosimetric advantages of using IMRT for the HN irradiation fields over opposed laterals or 2 posterior oblique fields were analyzed. Several beam arrangements were tried and the optimal IMRT beam arrangement was found to be an isocentric 7-fields plan. IMRT technique applying a $6 \mathrm{MV}$ photon beam with gantry angles of 205, 260, 310, 0, 50, 100 and 155 degrees (IEC scale) and collimator angle increases of 5 degrees from -15 to +15 degrees. The dose for the $\mathrm{HN}$ irradiation fields was normalized so the $95 \%$ of the PTV accepted $100 \%$ of the prescription dose of $70 \mathrm{~Gy}$, a level selected by the physician after reviewing the isodose outlines. This isodose outlines lead to coverage similar to the conventional conformal 3D-CRT plans. Figure (2) shows typical dose distribution IMRT for seven fields.

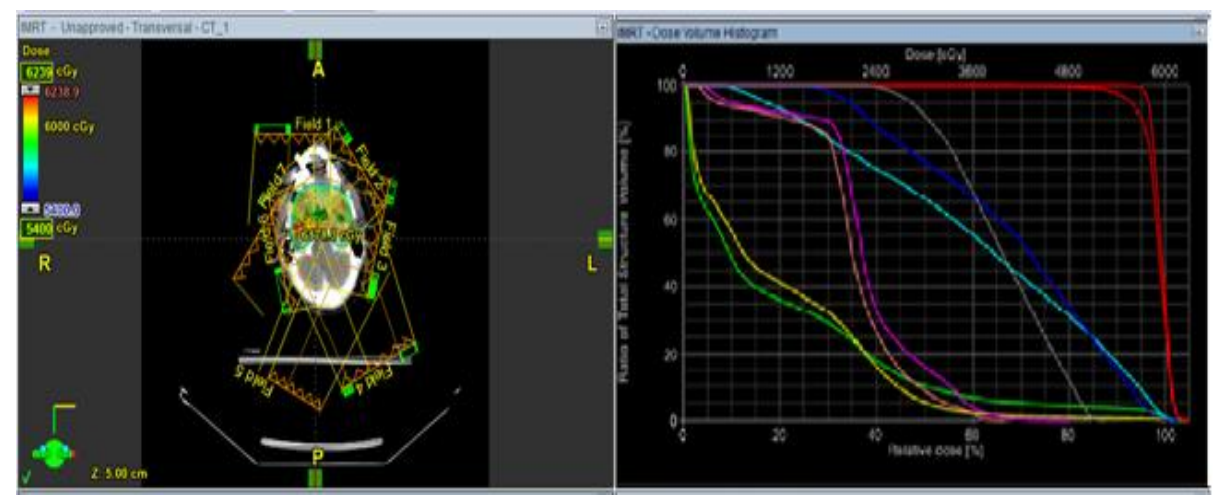

Figure (2): CT image of the axial view and DVH for HN plan with IMRT plan

3- Rapid Arc (VMAT) treatment techniques for VMAT radiation therapy planningprotocol:

As with the IMRT technique, the dosimetric advantages of VMAT over opposed lateral 3D-CRT or 2 posterior oblique fields were investigated for the $\mathrm{HN}$ irradiation fields first. The 
Rapid Arc planning is done through inverse planning methods in the same arrangement as that of IMRT. This is further complicated due to increased number of dynamic variables involved during delivery. Varian's solution is the presentation of a novel determination-based optimization algorithm to help in the inverse planning process. Although the clinical advantages of arc techniques that consider a process providing a simple solution for the inverse planning process is yet to be established. As a result, there is a strong relationship between the skills of the planner and the result of plan quality. Single $360^{\circ}$ VMAT arc or dual VMAT arcs $360^{\circ}$ (clockwise and counter-clockwise) were used with a collimator angle of $45^{\circ}$ for the clockwise arc and $315^{\circ}$ for the counter-clockwise arc. All VMAT plans need certain degree of collimator rotation to decrease the increasing tongue and groove leakage effects (for MLC) during gantry rotation, and to allow spatial modulation in the transverse plane and to avoid treating through the arms. The dose was normalized as with the IMRT technique so $95 \%$ of the PTV accepted $100 \%$ of the prescription dose. Figure (3) shows typical dose distribution VMAT for two $360^{\circ}$ Arcs.

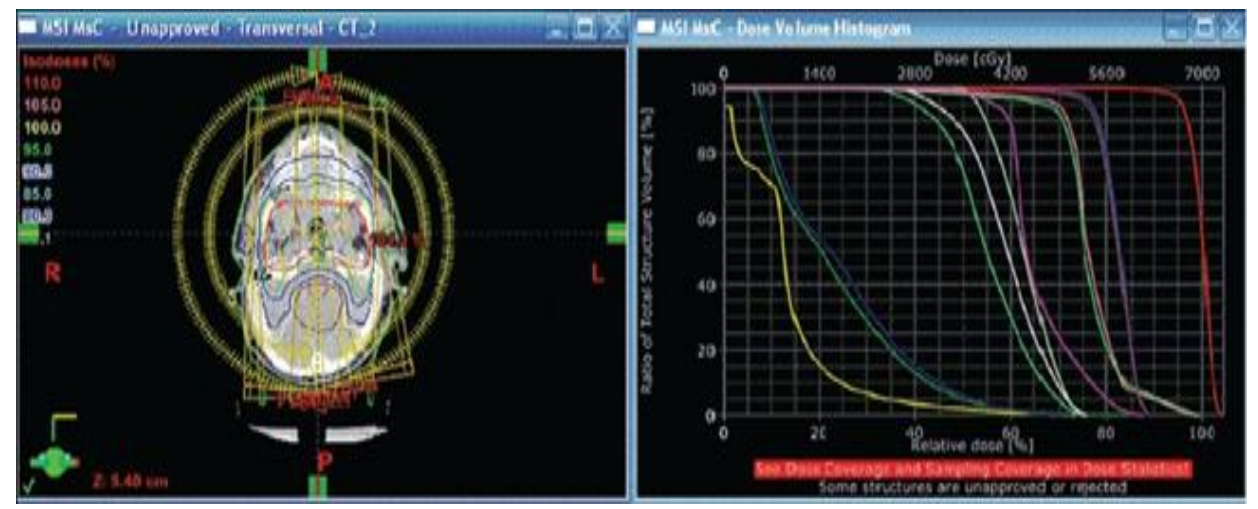

Figure (3): CT image of the axial view and DVH for prostate plan with for VMAT plan

\subsection{Evaluation of Treatment Plan and Plan Quality Comparison}

- Dosimetric parameters to analyze target coverage and dose distribution in the PTV are as follows;

(1) Mean dose,

(2) $\mathrm{V}_{\mathrm{n}} \mathrm{Gy}$, percentage of the volume receiving radiation $\geq \mathrm{n}$ Gy,

(3) $\mathrm{D}_{95} \%$, minimum dose to $95 \%$ of the PTV,

(4) $\mathrm{D}_{2} \%$, maximum dose to $2 \%$ of the PTV,

(5) Conformity index (CI): VR/VT, defined as the volume covered by the $95 \%$ isodose (VR) divided by the PTV volume (VT). Ideally, it should lie between 0.9 and 2.0. The smaller the value of $\mathrm{CI}$, the better the conformal coverage.

(6) Homogeneity index (HI): IMAX/IR, defined as a ratio evaluating the dose homogeneity in PTV, where IMAX is the maximum isodose inside the target volume and IR is the reference isodose (95\% isodose line). Ideally, it should be less than 2. Lower homogeneity index value indicates a more homogeneous target dose and a higher $\mathrm{HI}$ indicates poorer homogeneity.

-For OAR, the analysis included the mean dose, the maximum dose expressed as D2\% and a set of appropriate $\mathrm{V}_{\mathrm{n}} \mathrm{Gy}$ and $\mathrm{D}_{\mathrm{n}}$ values. 
-For healthy tissue, we detailed the volume of the body minus PTV receiving low doses $\left(\mathrm{V}_{5}, \mathrm{~V}_{10}\right.$, and $\mathrm{V}_{20} \mathrm{~Gy}$ ).

-The number of MU per fraction required for each plan and the treatment delivery time (from beam-on to beam-off).

\subsection{Dosimetric Evaluation}

In the process of validation of the DVH software [Taweap S. et al, 2013], [Feygelman, V. et al, 2013], other QA tools have also been used, including three methods for quality assurance first method PTW 2D array with Octavius 4D phantom including DVH software (PTW demo Verisoft version 7.0. software - Freiburg, Germany), Second method portal dosimetry (EPID) and third method EBT2 radiochromic film (Ashland Inc.) as tool in the process of validation of the DVH software for assessment the dose distribution in patient with head \& neck cancer.

Verisoft EPID option and Verisoft filmscan option is a software option tool that converts any electronic portal imaging device (EPID) image or film data to dose for analysis in the 2D array DVH software. Figure (4) shows typical 2D Array and setup for measurements.

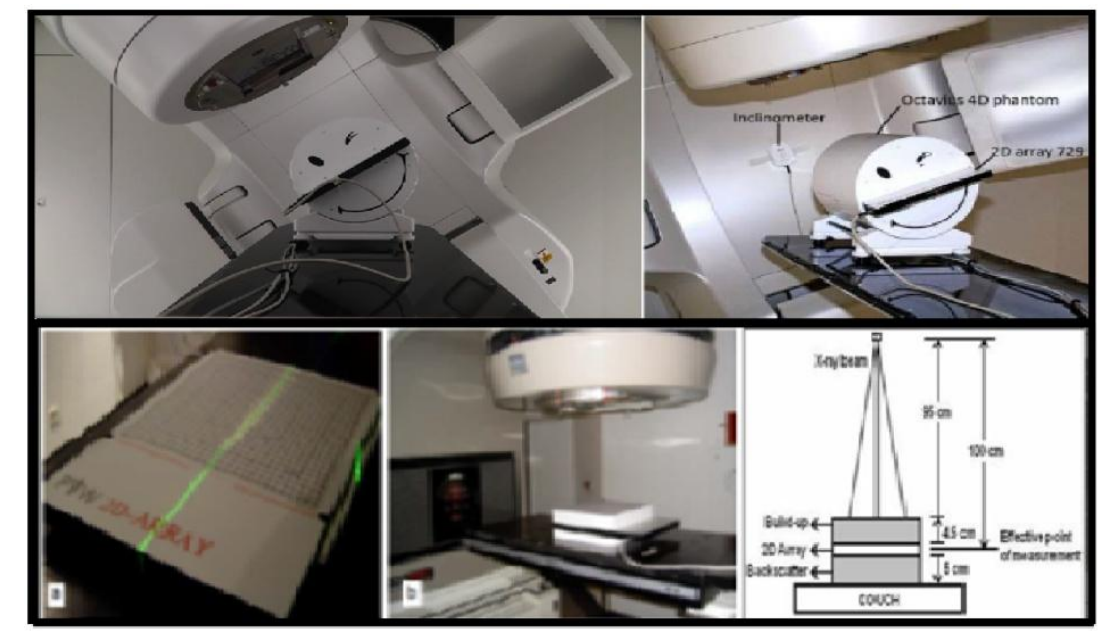

Figure (4): 2D Array forIMRT and VMAT plan verification with Octavius 4D phantom and its setup indifferent measurement techniques

\subsection{Gamma evaluation (Gamma Analysis)}

Gamma index $(\Gamma)$ is the standard statistical method for planar dose verification in IMRT QA and is determined by the ratio of the dose difference (DD) and the dose to agreement (DTA) between the outlined and the measured plan for each point of interest.

The 2D dose planes calculation for isocenter level in the TPS were transferred to the Verisoft device software for assessment using the Gamma analysis method produced by Low et al. The approval criteria of $3 \mathrm{~mm}$ for the distance to agreement (DTA) and $3 \%$ for dose 
difference level were selected. Also the percentage of the assessed dose points passing for the gamma index was kept at a limit $95 \%$.

\subsection{MLC bank errors}

MLC bank positioning errors can occur in new treatment technique delivery due to the inaccurate positioning of an individual leaf or due to systematic shifts in MLC or leaf bank carriage. Possible reasons for individual leaf positioning errors reported in literature are due to gradual degradation of performance of each motor, cable imperfections, and loss of counts of potentiometer encoders. Leaf calibration process is reported probably to be the main cause for systematic error in leaf bank [Rowshanfarzad P. et al, 2012]. From copy of the original plan, a new plan was created which contained an introduced error, based on realistic machine calibration errors. The following modification was introduced; a widening of the MLC bank with 1mm on special side (X1 jaw). The error was above or on the limit of tolerance levels of regular QA checks as defined and recommended by AAPM Task Group 119. The effect of the errors in the modified plans was analyzed by comparing the original plan (the plan without errors) with the corresponding plans with intentional error in the TPS. Comparison of dose distributions was made by a gamma evaluation in three dimensions using DVH software (PTW demo Verisoft version 7.0. software - Freiburg, Germany) were compared for the gross tumor volume (GTV), PTV, and one of the organs at risk (OAR). A common tolerance level for the gamma index evaluation is a pass rate of $95 \%$, and an error was considered detected when the gamma failure rate was higher than $5 \%$.

\section{Results and Discussion}

\subsection{Comparison of treatment plans}

TPS software was allowing us to view the dose distributions and DVH data for all plans in a single environment. A comparison of a whole delivery time of treatment and total monitor unit (MU) delivery between the 3D-CRT, IMRT and VMAT plans was done for all cases.

\subsection{Plan evaluation}

Head and Neck irradiation poses a challenging planning process because of the complex target volume.In the present study, IMRT plans were compared with VMAT and 3DCRT plans. Various dose-volume parameters to assess OAR sparing were studied. Plan quality was assessed by comparing dose HI, CI, target coverage, low isodose volumes, monitor units and treatment time.

During the latest few years, IMRT and VMAT have been increasingly applied to treat cancer of H\&N to allow more conformal dose distribution and a rapid increase of dose. On the other hand, volumes of OAR to low doses of radiation with IMRT and VMAT are greater than 3DCRT techniques.IMRT employs extra radiation fields, thus covering a bigger volume of normal tissue that is received the lower levels of doses and IMRT needs the accelerator to be powerful for long-term of MUs, causing in additional dose of total body due to the widespread of scatter radiation. The quantity of secondary radiation generated is a linear function of the quantity of monitor units (MUs). IMRT is connected with a 2 to 4 greater than normal number of MUs counterweight with standard conformal planning as illustrated in Table (2). 
Table (2): HN cases (20 patients): Plan comparison between IMRT, VMAT, and 3DCRT

\begin{tabular}{|c|c|c|c|c|c|}
\hline & & 3DCRT & IMRT & single arc & dual arc \\
\hline \multirow[t]{7}{*}{ PTV70 } & \multirow{2}{*}{$\begin{array}{l}\mathrm{HI} \\
\mathrm{CI}\end{array}$} & $0.09 \pm 0.01$ & $0.09 \pm 0.01$ & $0.07 \pm 0.01$ & $0.07 \pm 0.01$ \\
\hline & & $0.50 \pm 0.07$ & $0.49 \pm 0.07$ & $0.57 \pm 0.09$ & $0.57 \pm 0.08$ \\
\hline & \multirow{2}{*}{$\begin{array}{c}\text { D2\% Gy } \\
\text { D50\% Gy }\end{array}$} & $76.57 \pm 0.66$ & $76.30 \pm 0.86$ & $75.43 \pm 0.76$ & $75.40 \pm 0.89$ \\
\hline & & $72.80 \pm 0.10$ & $72.93 \pm 0.11$ & $\begin{array}{l}75.43 \pm 0.76 \\
72.64 \pm 0.03\end{array}$ & $72.68 \pm 0.03$ \\
\hline & D95\% & $97.9 \pm 1.3 \%$ & $98.0 \pm 1.0 \%$ & $97.5 \pm 1.5 \%$ & $98.1 \pm 1.1 \%$ \\
\hline & D98\% Gy & $70.02 \pm 0.40$ & $70.01 \pm 0.44$ & $70.01 \pm 0.45$ & $70.15 \pm 0.57$ \\
\hline & max. point & $7160 \pm 101 \mathrm{cGy}$ & $7050 \pm 218 c G y$ & $7120 \pm 151 \mathrm{cGy}$ & $7086 \pm 48$ cGy \\
\hline \multirow[t]{6}{*}{ PTV59.4 } & $\mathrm{HI}$ & $0.23 \pm 0.02$ & $0.23 \pm 0.02$ & $0.21 \pm 0.02$ & $0.21 \pm 0.02$ \\
\hline & $\mathrm{Cl}$ & $0.73 \pm 0.04$ & $0.73 \pm 0.03$ & $0.76 \pm 0.03$ & $0.76 \pm 0.04$ \\
\hline & D2\% Gy & $73.20 \pm 0.79$ & $72.89 \pm 1.16$ & $72.45 \pm 1.11$ & $72.42 \pm 1.26$ \\
\hline & D50\% Gy & $63.83 \pm 0.17$ & $63.99 \pm 0.19$ & $64.14 \pm 0.28$ & $63.64 \pm 0.11$ \\
\hline & D95\% Gy & $60.17 \pm 0.27$ & $60.20 \pm 0.17$ & $60.42 \pm 0.18$ & $60.44 \pm 0.12$ \\
\hline & D98\% Gy & $58.55 \pm 0.41$ & $57.99 \pm 0.50$ & $58.49 \pm 0.32$ & $58.83 \pm 0.39$ \\
\hline \multirow[t]{3}{*}{ Brain stem } & D2\% Gy & $46.32 \pm 0.44$ & $42.56 \pm 0.48$ & $41.21 \pm 0.92$ & $41.94 \pm 0.42$ \\
\hline & Dmean Gy & $27.51 \pm 0.41$ & $24.85 \pm 3.86$ & $24.02 \pm 2.58$ & $23.46 \pm 3.97$ \\
\hline & Dmax Gy & $31.1(6.3-46.4)$ & $30.6(16.0-47.0)$ & $30.8(6.3-45.3)$ & $30.4(13.7-42.7)$ \\
\hline \multirow[t]{3}{*}{ Spinal-cord } & D2\% Gy & $28.66 \pm 3.02$ & $33.60 \pm 2.67$ & $35.15 \pm 1.75$ & $32.59 \pm 2.91$ \\
\hline & Dmean Gy & $22.3 \pm 3.52$ & $25.01 \pm 2.79$ & $26.26 \pm 2.66$ & $23.46 \pm 2.74$ \\
\hline & Dmax Gy & $28.0(14.4-34.4)$ & $27.3(20.8-39.9)$ & $27.8(14.4-34.8)$ & $26.8(18.1-36.6)$ \\
\hline \multirow[t]{2}{*}{ Chiasm } & Dmax Gy & $48.23 \pm 6.32$ & $47.17 \pm 5.83$ & $47.51 \pm 4.52$ & $47.89 \pm 5.01$ \\
\hline & Dmean Gy & $36.37 \pm 7.30$ & $35.30 \pm 5.46$ & $34.44 \pm 6.88$ & $36.38 \pm 5.79$ \\
\hline \multirow[t]{2}{*}{ Optic N L } & Dmax Gy & $41.11 \pm 10.00$ & $44.13 \pm 9.52$ & $43.73 \pm 10.41$ & $46.20 \pm 9.77$ \\
\hline & Dmean Gy & $23.22 \pm 9.24$ & $24.40 \pm 8.29$ & $24.17 \pm 9.69$ & $26.17 \pm 9.69$ \\
\hline \multirow[t]{2}{*}{ Optic N R } & Dmax Gy & $40.84 \pm 8.91$ & $42.04 \pm 10.18$ & $43.30 \pm 11.85$ & $44.88 \pm 9.57$ \\
\hline & Dmean Gy & $22.04 \pm 9.15$ & $23.92 \pm 8.74$ & $25.04 \pm 9.69$ & $25.66 \pm 9.53$ \\
\hline lenses & Dmean Gy & $2.22 \pm 1.38$ & $4.21 \pm 1.21$ & $3.71 \pm 1.05$ & $4.35 \pm 1.7$ \\
\hline \multirow[t]{3}{*}{ Parotid glands } & Dmean Gy & $31.65 \pm 3.08$ & $30.11 \pm 3.93$ & $34.14 \pm 3.56$ & $32.47 \pm 3.83$ \\
\hline & D50\% Gy & $47 \pm 11 \%$ & $47 \pm 05 \%$ & $40 \pm 25 \%$ & $24 \pm 12 \%$ \\
\hline & Dmax Gy & $3895 \pm 50$ cGy & $3230 \pm 300 \mathrm{cGy}$ & $2500 \pm 410 \mathrm{cGy}$ & $2480 \pm 430 \mathrm{cGy}$ \\
\hline Oral cavity & Dmean Gy & $43.21 \pm 5.60$ & $41.42 \pm 6.77$ & $40.35 \pm 4.77$ & $36.99 \pm 6.18$ \\
\hline Larynx & Dmean Gy & $34.76 \pm 3.82$ & $35.86 \pm 3.05$ & $37.67 \pm 4.13$ & $35.17 \pm 4.55$ \\
\hline Total body & Dmean Gy & $10.0(5.7-18.0)$ & $9.7(5.5-17.2)$ & $10.0(5.9-17.8)$ & $9.9(5.3-18.1)$ \\
\hline MUs & & $1090.2 \pm 91.1$ & $1492.2 \pm 120.7$ & $1232.1 \pm 146.2$ & $1349.9 \pm 133.8$ \\
\hline Delivery time (min) & & $<5$ min & $15-20 \mathrm{~min}$ & $5-8 \mathrm{~min}$ & 5-10 min \\
\hline Mean dose rate & (MU/min) & $86.6 \pm 5.1$ & $249.8 \pm 17.9$ & $494.0 \pm 38.6$ & $379.6 \pm 30.1$ \\
\hline Control points & & $138.0 \pm 10.4$ & $126.6 \pm 10.2$ & $161.4 \pm 13.1$ & $187.0 \pm 30.9$ \\
\hline plan calculation time & (hour) & $0.8 \pm 0.4$ & $0.8 \pm 0.3$ & $5.6 \pm 1.4$ & $4.8 \pm 1.2$ \\
\hline \multicolumn{2}{|l|}{ QA passing rate $(\%)$} & $99.3(99.0-99.6)$ & $98.3(96.0-99.8)$ & $97.5(96.0-98.3)$ & $97.7(96.1-99.3)$ \\
\hline
\end{tabular}

In the current study, 3D-CRT had the highest PTV and provided the most efficient delivery but had the highest mean dose to all organs at risk (OAR) with the highest parotid dose. The IMRT technique was more efficient than single VMAT arc and had the higher planned target volume (PTV) maximum, whereas the dual VMAT arcs technique provided the greatest parotid sparing with better efficiency. IMRT provides the longest delivery time but the greatest OAR sparing. IMRT and VMAT delivered very extremely and comparable conformal plans for tumor coverage than 3D-CRT. The dose homogeneity inside the PTV was a little improved by the VMAT technique while compared with IMRT, in spite of the alteration was not statistically important. Compared treatment and dosimetric priority between VMAT and IMRT plans were to get together the aims for PTV and the limit for organs than 3DCRT plan. The Planning Target Volume (PTV) coverage was found to be similar for IMRT and VMAT, with both techniques having superior conformity index (CI) and homogeneity index (HI) compared to 3D CRT.The intensity modulated techniques produce treatment plans of considerably improved quality and greater MUs during the time that compared to 3D-CRT, as shown in Figures (1 and 2). As show in the current study the better treatment efficiency for the arc therapy vs. Dynamic IMRT. The current study also showed overall similar dose distributions with slight advantages regarding dose to OAR and conformity for the plans with variable dose rate during rotation for most head and neck cases. 
But in specific cases where high-rise of dose modulation is desired around small OARs, a suitable plan might clinically only be achievable with IMRT. As VMAT needs a long-term computation time, difficult plans can critically decrease the clinical efficiency and should be chosen carefully. With these results in mind, the most useful method of treating the $\mathrm{HN}$ irradiation fields is to use the IMRT technique. Overall, taking into account both efficiency and dosimetry, IMRT for the HN PTV is the technique of choice.

It is critical to remember that this method is not appropriate for all patients since it can be inefficient, but it is suitable for cases with dose modulation is desired around small OARs which can benefit from a higher, definitive dose.Also, higher systematic errors in IMRT QA than VMAT QA due to the more complicated setup used in IMRT QA. The variation of random errors was also larger in IMRT QA than VMAT QA because the VMAT plan has more continuity of dose distribution which implied that the VMAT QA process was more accurate than the IMRT QA process.

3.3. Demonstration and validation for (IMRT) quality assurance (QA) passing rates to expect dose errors in PatientNo. (10)

This part from the study investigates the impact of systematic multi-leaf collimator (MLC) bank positional errors on gamma analysis results used for quality assurance (QA) of IMRT treatment technique. The novelty is right to investigate the correlation between Gamma index passing rate \%GP obtained during standard per-beam pretreatment QA tests of actual clinical plans, with acceptance (bank positional error) dose discrepancy, between planned dosevolume-histogram (DVH) and patients' predicted DVH, calculated by DVH software (PTW demo Verisoft version 7.0. software - Freiburg, Germany) In addition, this study evaluates the relationship of these gamma analysis results and clinical dose volume histogram metrics (DVH) for treatment technique. For each PTV, we took into account as control point dose values $\mathrm{D}_{\text {Mean }}$ and $\mathrm{D}_{95} \%$ (dose to $95 \%$ volume). For OARs, we took into account as control point dose values $\mathrm{D}_{\text {Mean }}$ for (oral cavity dose and right / left parotid dose) and control point dose values $\mathrm{D}_{\mathrm{Max}}$ for (mandible, spinal cord dose, larynx dose, and brainstem dose).

The DVH software was used together with 2D array detector with $6 \mathrm{MV}$ photons from a Linear accelerator equipped with aMillennium 120 MLC. Verisoft (DVH version 7.0 software comparedtwo dimensional (2D) dose distributions measured at a depth of $50 \mathrm{~mm}$, to 2D distributions calculated at the same depth bythe TPS. The batch analysis of the per-beam comparisongenerated a file that is imported into DVH along with 4DICOMfiles exported from TPS (RT-Dose, RT-Structures,RT-Plan, and CT-images). DVH compares the calculated dosematrix andcalculatesthe3Dlocaland global Gamma indices. The software also calculatesDVHsforallstructuresimported.The measurements were performed at source axis distance $(\mathrm{SAD})=100 \mathrm{~cm}$ to ensure that the plan is delivered with the same process as if the patient was on the treatment couch at $\mathrm{SSD} / \mathrm{SAD}=100 \mathrm{~cm}$. For the clinicians, it would be of interest to know the impact on the doses to normal tissues and target volumes with the available IMRT dose QA outcomes. We have applied DVH (2D array PTW) software to 20 HN IMRT QA measurements. The whole of IMRT QA in planar evaluation had high Gamma passing rates under our " $3 \% / 3 \mathrm{~mm}$ " criteria. However, there can be significant errors in metrics of dose computation from TPS related to those resulted from actual measurements as illustrated in 
Table (3).

Table (3): the relative dose variations between TPS calculation and measurement for all $20 \mathrm{HN}$ patients' structures

\begin{tabular}{|c|c|c|c|c|c|c|c|c|c|}
\hline Patient & $\Gamma(3 \% / 3 \mathrm{~mm})$ & $\operatorname{PTV}(D 95)$ & Brainstem & Spinal Cord & Lt. Parotid & Rt. Parotid & Larynx & Mandible & Oral Cavity \\
\hline 1 & $98.32 \%$ & $1.18 \%$ & $-1.11 \%$ & $1.55 \%$ & $-0.35 \%$ & Inside PTV & $-0.17 \%$ & $-1.84 \%$ & $-1.29 \%$ \\
\hline 2 & $98.70 \%$ & $-0.51 \%$ & $0.99 \%$ & $-2.81 \%$ & $0.23 \%$ & $2.71 \%$ & $-1.00 \%$ & $-1.90 \%$ & $2.36 \%$ \\
\hline 3 & $98.51 \%$ & $0.33 \%$ & $-0.06 \%$ & $-0.63 \%$ & $-0.06 \%$ & $2.71 \%$ & $-0.59 \%$ & $-1.87 \%$ & $0.54 \%$ \\
\hline 4 & $96.03 \%$ & $-0.69 \%$ & $6.61 \%$ & $-1.90 \%$ & $5.03 \%$ & $1.17 \%$ & Out of field & $2.96 \%$ & $2.28 \%$ \\
\hline 5 & $96.67 \%$ & $-1.25 \%$ & $4.08 \%$ & $0.69 \%$ & $3.05 \%$ & $1.21 \%$ & $0.90 \%$ & $0.59 \%$ & $1.72 \%$ \\
\hline 6 & $97.32 \%$ & $-1.81 \%$ & $1.56 \%$ & $3.27 \%$ & $1.06 \%$ & $1.26 \%$ & $-1.17 \%$ & $-1.77 \%$ & $1.17 \%$ \\
\hline 7 & $96.82 \%$ & $-1.44 \%$ & $1.47 \%$ & $2.60 \%$ & $3.17 \%$ & $2.13 \%$ & $-1.73 \%$ & $-0.23 \%$ & $2.19 \%$ \\
\hline 8 & $96.33 \%$ & $-1.07 \%$ & $1.39 \%$ & $1.92 \%$ & $5.28 \%$ & $2.99 \%$ & $-2.30 \%$ & $1.32 \%$ & $3.22 \%$ \\
\hline 9 & $96.72 \%$ & $-2.75 \%$ & $-0.36 \%$ & $0.22 \%$ & $2.07 \%$ & $-0.08 \%$ & $-2.25 \%$ & $-0.09 \%$ & $1.73 \%$ \\
\hline 10 & $98.20 \%$ & $-4.43 \%$ & $-2.11 \%$ & $-1.48 \%$ & $-1.13 \%$ & $-3.15 \%$ & $-2.21 \%$ & $-1.49 \%$ & $0.24 \%$ \\
\hline 11 & $97.42 \%$ & $-3.01 \%$ & $-0.80 \%$ & $-0.88 \%$ & $-0.83 \%$ & $0.46 \%$ & $0.30 \%$ & $0.14 \%$ & $2.40 \%$ \\
\hline 12 & $97.71 \%$ & $-1.60 \%$ & $0.51 \%$ & $-0.28 \%$ & $-0.54 \%$ & $4.07 \%$ & Inside PTV & $1.77 \%$ & $4.56 \%$ \\
\hline 13 & $97.81 \%$ & $-2.10 \%$ & $0.93 \%$ & $-1.34 \%$ & $0.39 \%$ & $2.97 \%$ & $0.89 \%$ & $-1.20 \%$ & $1.29 \%$ \\
\hline 14 & $97.91 \%$ & $-2.60 \%$ & $1.35 \%$ & $-2.40 \%$ & $1.32 \%$ & $1.88 \%$ & $-1.07 \%$ & $-4.17 \%$ & Inside PTV \\
\hline 15 & $97.47 \%$ & $-1.42 \%$ & $1.96 \%$ & $-1.14 \%$ & $3.28 \%$ & $2.43 \%$ & $-1.01 \%$ & $-1.71 \%$ & $1.45 \%$ \\
\hline 16 & $97.02 \%$ & $-0.24 \%$ & $2.57 \%$ & $0.12 \%$ & $5.24 \%$ & $2.99 \%$ & $-0.96 \%$ & $0.75 \%$ & $4.54 \%$ \\
\hline 17 & $97.56 \%$ & $-0.44 \%$ & $1.42 \%$ & $0.98 \%$ & $1.42 \%$ & $1.86 \%$ & $0.27 \%$ & $1.30 \%$ & $2.58 \%$ \\
\hline 18 & $98.11 \%$ & $-0.64 \%$ & $0.27 \%$ & $1.84 \%$ & Inside PTV & $0.72 \%$ & $1.49 \%$ & $1.85 \%$ & $0.62 \%$ \\
\hline 19 & $96.92 \%$ & $-1.81 \%$ & $1.11 \%$ & $0.30 \%$ & $0.81 \%$ & $1.32 \%$ & $-0.05 \%$ & $0.79 \%$ & $1.07 \%$ \\
\hline 20 & $95.73 \%$ & $-2.97 \%$ & $1.95 \%$ & $-1.23 \%$ & $2.76 \%$ & $1.91 \%$ & $-1.60 \%$ & $-0.28 \%$ & $1.51 \%$ \\
\hline Mean & $97.31 \%$ & $-1.46 \%$ & $1.19 \%$ & $-0.03 \%$ & $1.70 \%$ & $1.66 \%$ & $-0.68 \%$ & $-0.25 \%$ & $1.80 \%$ \\
\hline St. dev. \% & $0.80 \%$ & $1.30 \%$ & $1.87 \%$ & $1.68 \%$ & $2.06 \%$ & $1.55 \%$ & $1.14 \%$ & $1.73 \%$ & $1.40 \%$ \\
\hline
\end{tabular}

For the dose distributions measured by detectors and calculated by TPS, when the gantry was fixed at $0^{\circ}$, the $\gamma$ pass rates with $3 \%$ maximum dose and $3 \mathrm{~mm} \gamma$ criteria were above $95.73 \%$. Table (5) shows the relative variations in doses between TPS computation and actual measurement for the whole of structures of $20 \mathrm{HN}$ patients at zero gantry angle in the IMRT plan.

Through a HN case study, case (Patient No. 10), as shown in Figure 5, where (2D) dose distributions measured at a depth of $50 \mathrm{~mm}$ compared to $2 \mathrm{D}$ distributions calculated at the similar depth by the TPS.

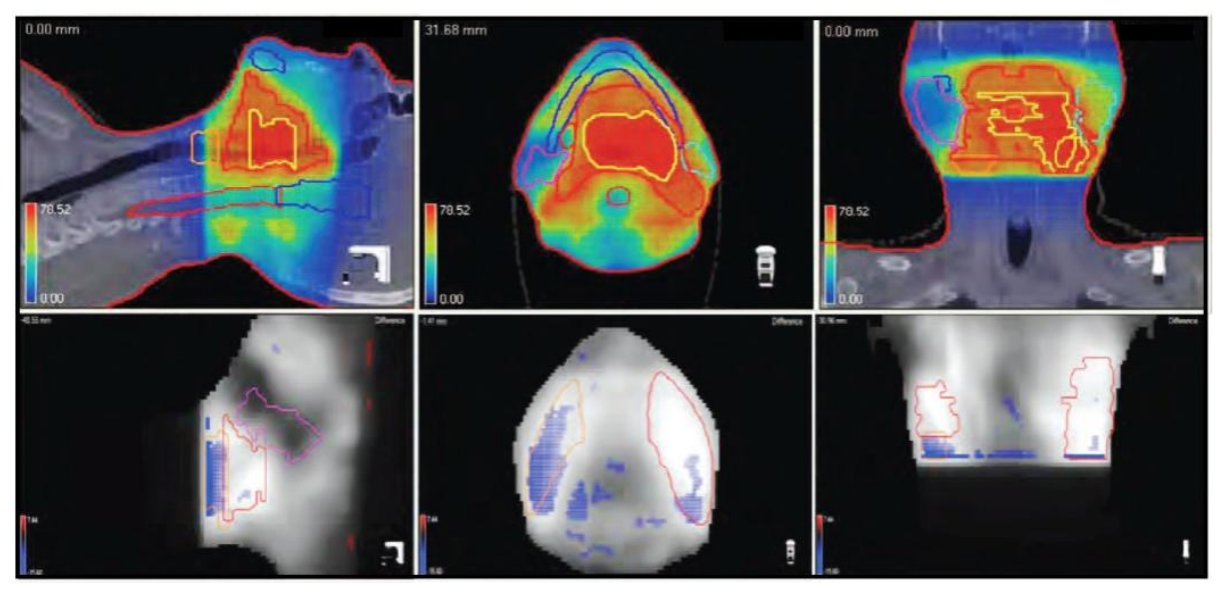




\section{Figure (5): GP\% for DD/DTA of $3 \% / 3 \mathrm{~mm}$ was high (98.2\%) \&2D images of the sagittal, axial and coronal views}

Figure 5 (upper data) shows the matching between the treatment plan and measurement (in Gy) through gamma analysis results. The colors (red, blue, and green) showed the passed or failed points and the pass rate for DD/DTA of 3\%/3 mm was high (98.2\%). In the lower 2D images of the axial, coronal and sagittal viewsby EPID QA in Figure 5, the blue cold zone illustrate the region of low dose at inferior dose edge in images of the sagittal, axial and coronal views.

The variations in dose are at the inferior of patient dose edge. Table 4 from DVH software(PTW demo Verisoft version 7.0. software - Freiburg, Germany) data shows all structures matched well except two small volumes, PTV (59.40 Gy) and Larynx. Their variations in dose in absolute and relative methods for $\mathrm{D}_{95}$ of PTV $(59.40 \mathrm{~Gy})$ and mean larynx dose $\mathrm{D}_{\text {Mean, }}$ respectively.

Table (4): Dose variations between calculated doses TPS and measured doses

\begin{tabular}{|cccccccc|}
\hline RoIName & $\begin{array}{c}\text { Volvme } \\
\text { Cm }\end{array}$ & $\begin{array}{c}\text { Control } \\
\text { Point }\end{array}$ & Unit & $\begin{array}{c}\text { Calculated } \\
\text { Dose }\end{array}$ & $\begin{array}{c}\text { Measured } \\
\text { Dose }\end{array}$ & $\begin{array}{c}\text { Dose Diff. } \\
\text { Gy }\end{array}$ & $\begin{array}{c}\text { Dose Diff. } \\
\%\end{array}$ \\
\hline Oral Cavity & 167.912 & Mean & Gy & 16.92 & 16.96 & 0.04 Gy & 0.21 \\
\hline Mandible & 66.144 & Mean & Gy & 46.13 & 44.72 & -1.4 & -3.04 \\
\hline Mandible & 66.144 & Max. & Gy & 71.88 & 70.96 & -0.92 & -1.28 \\
\hline Spinal Cord & 42.72 & Max. & Gy & 42.52 & 41.98 & -0.54 & -1.27 \\
\hline Spinal Cord & 42.72 & Do1 & Gy & 38.37 & 37.02 & -1.35 & -3.53 \\
\hline GTV & 3.096 & Mean & Gy & 75.78 & 75.39 & -0.4 & -0.52 \\
\hline GTV & 3.096 & Max. & Gy & 78.43 & 77.68 & -0.75 & -0.95 \\
\hline Larynx & 15.432 & Mean & Gy & 36.67 & 33.74 & -2.93 & -7.99 \\
\hline Larynx & 15.432 & Max. & Gy & 65.39 & 64.15 & -1.24 & -1.9 \\
\hline Submandible & 8.456 & Mean & Gy & 26.6 & 25.95 & -0.65 & -2.43 \\
\hline Submandible & 8.456 & Max. & Gy & 54.38 & 53.35 & -1.03 & -1.89 \\
\hline Rt. Parotid & 40.336 & Mean & Gy & 20.72 & 20.16 & -0.56 & -2.7 \\
\hline Lt. Parotid & 30.104 & Mean & Gy & 50.85 & 50.36 & -0.49 & -0.97 \\
\hline Brainstem & 42.592 & Max. & Gy & 47.11 & 46.26 & -0.85 & -1.81 \\
\hline PTV70 & 136.976 & Mean & Gy & 74.24 & 73.5 & -0.74 & -1 \\
\hline PTV70 & 136.976 & Max. & Gy & 78.43 & 78.52 & 0.09 & 0.12 \\
\hline PTV70 & 136.976 & D95 & Gy & 70.23 & 69.03 & -1.2 & -1.7 \\
\hline PTV59.4 & 19.344 & Mean & Gy & 61.96 & 58.58 & -3.38 & -5.46 \\
\hline PTV59.4 & 19.344 & Max. & Gy & 69.34 & 68.63 & -0.71 & -1.02 \\
\hline PTV59.4 & 19.344 & D95 & Gy & $\mathbf{5 3 . 0 4}$ & 48.84 & -4.2 & -7.93 \\
\hline PTV54 & 404.6 & Mean & Gy & 68.79 & 67.72 & -1.06 & -1.55 \\
\hline PTV54 & 404.6 & Max. & Gy & 78.43 & 78.52 & 0.09 & 0.12 \\
\hline PTV54 & 404.6 & D95 & Gy & 61.27 & 58.94 & -2.33 & -3.8 \\
\hline
\end{tabular}

DVH software indicated that these two structures [Larynx and PTV (59.40Gy)] had less dose than the TPS estimated and a cold dose zone was at the inferior edge of the dose cloud, particularly on the right side of patient and inside the PTV (59.40 Gy). 
In order to verify whether the errors initiated through DVH software accurately, we had to discover all causes of the errors, such as:

1- Measurement device accuracy in this zone (under dose measurement)

2- And/or TPS calculation accuracy in this zone (over dose assessment).

First, we cross checked the DVH (2D array PTW) software measurement with EPID to determine if the error was real. Upon examining the position of cold spots by EPID, a cold zone was initiated at the inferior of dose edge as shown in the lower $2 \mathrm{D}$ images in Figures $(\mathbf{5} \& \mathbf{6})$ at the inferior edge of jaw. Besides, Figure 6 shows the difference in dose volume histogram for the whole of structures in view of DVH software.

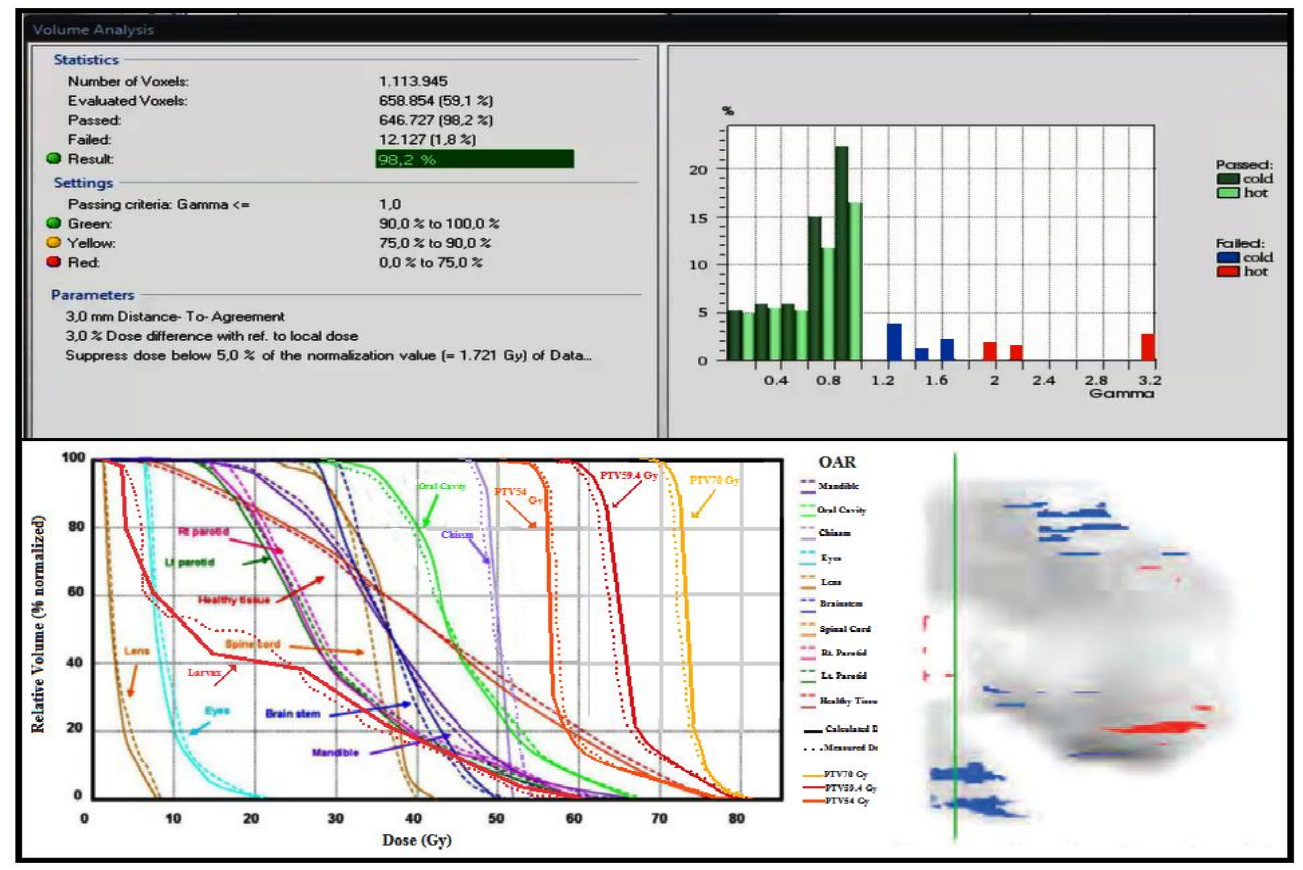

\section{Figure (6): Dose variations in the DVHs, EPID QA and dose difference map}

As shown in Figure 6, DVH software, the software computes DVHs (upper data) for the whole of structures imported as illustrated in Figure 6 (TPS calculated doses in solid lines vs. measured doses in dotted lines). Also, shows the colors (red, blue, and green) of dose difference map which show overestimated, underestimated, and matching doses between the predicted in treatment plan and measured in QA system, respectively.

In the Figure 6 : Red, green, and blue represent the measured doses higher, matching, and lower than the planned doses, respectively for $3 \% / 3 \mathrm{~mm}$ criteria. From dose differences in the DVHs and dose difference map (lower right) of 2D array and EPID 2D QA (lower left), 2D ARRAY and EPID are consistent in the region of overdosing area compared to TPS calculated doses.As shown in Figure 6, the IMRT plan had a seven beams and the whole of beams had collimator angle of 90 degrees, meaning that the matched inferior edges correspond to the beams $\mathrm{X}_{1}$ jaw. 
The measured EPID results were matched very well, even at the $X_{1}$ jaw edge where the cold (blue) zone was located. EPID would detect very small zone errors, such as Tongue and Groove(of MLC), which were nearly difficult for any other array to detect. As shown in figure, as known previously in section (MLC bank errors), there was a TPS error (TPS over predicting dose) in the lower left dose of the area that divided into two branches. The pass rate for DD/DTA of $3 \% / 3 \mathrm{~mm}$ was high $(98.2 \%)$ for the detector result but we believe that $3 \% / 3 \mathrm{~mm}$ is not a stringent tool. Notice that the whole lower region was over predicted (by TPS) and the error was not limited to the gap $(1 \mathrm{~mm})$ is the mis-calibration of the $\mathrm{X}_{1}$ jaw column. Note that EPID even emphasized the Tongue and Groove effects (horizontal red markers in high dose and blue markers in low dose region) as shown in Figure 6. There was a consistent difference (measurement vs.TPS) for the area that divided into two branches of target regions, evidenced by two measurement methods (2D array and EPID). However, conventional passing rates, and especially the Gamma analyses, are confirmed for allowing critical high gradient errors go undetected. From this case study, we had corrected the X1 jaw calibration right away and recalculated the TPS IMRT fields accounting for the Tongue and Groove effect. The DVH result showed a significant improvement for the two small volumes doses [PTV (59.40 Gy) and Larynx] from almost $8 \%$ reducing to $<2 \%$ differences in dose.

Almost dose QA procedures have been depended on available devices and practicality, such as comparing TPS computed doses against 2D dose actual measurements by film, array detectors, and computed radiography (CR). Most patient specific IMRT dose QA as recommended by the AAPM Task Group 119use 3\%/3 $\mathrm{mm}$ as Gamma index. The other studies found that the Gamma criterion of $3 \% / 3 \mathrm{~mm}$ (or $2 \% / 3 \mathrm{~mm}$ ) was too permissive to detect systematic errors, especially when used in TPS commissioning. Therefore, to predict clinically relevant patient dose errors, IMRT QA should include the evaluation of patient anatomy based metrics directly related to the clinical impact of the dose error.

Our research has emphasized the vital importance of progressing from IMRT dose QA phantom with Gamma based to DVH for patient measurements. The TPS has some minor problems in small modulated regions, which are more predominant in complex HN cases. Almost of these minor problems might not be discovered in regular QA. Small alterations in DMLC output might lead to significant problems in metrics of clinical dose due to special effects gravitational force on DMLC.

\section{Conclusions}

With the introduction of complex technologies in modern radiotherapy, more accurate and efficient methods are required to ensure correct delivery of treatments.Radiotherapy is an essential part in the treatment of HN cases malignancy.

In adult patients requiring $\mathrm{HN}$ irradiation fields, IMRT and VMAT planning provide more homogenous target coverage while decreasing dose to several critical organs when compared with the conventional conformal 3D-CRT. In Current study emphasis that VMAT has not considerably better conformity and homogeneity but VMAT has upper volume of low doses 
than IMRT. VMAT spread low doses of radiation to greater zones of normal tissue. This compliance with standards comes with an incompatible feature of greater treatment times and spread of low dose that might present potential of secondary malignancies, particularly for the VMAT technique. For patients that can benefit from a definitive, higher dose, considering efficiency of the monitor unit, delivery time, and dosimetric parameters like un-resectable disease, the most clinically feasible technique is to use IMRT beams for the HN portion of the PTV. Although this technique results, this study emphasis that performance of conventional IMRT QA metrics (Gamma passing rates) are not expect the dose errors in the organs at risk and PTV. Clinically the patient dose QA has given us the opportunity for to expect the patient specific dose volume relationships.

On the basis of the wide range of analysis and correlation study, they conclude that there is no assured correlation or notable pattern that could provide relation between the results of gamma test and dose volume histogram metrics (DVH) for treatment technique plan

The dosimetry estimation presented in this study present important data for the radiation oncology staff to justify whether a correlation of Gamma passing rates and patient DVH with TPS model is necessary in respectable agreement during treatment. These data may, therefore, be useful in the development of an adaptive dosimetry scheme (periodic adjustment of the conformal treatment plan with performance of QA metrics tools and Linear accelerator calibration) that takes into account such QA methods and Gamma index acceptance criteria.

\section{References:}

Bailey, D. W., Nelms, B. E., Attwood, K., Kumaraswamy, L., Podgorsak, M. Statistical variability and confidence intervals for planar dose QA pass rates. Med Phys 38, 6053-6064 (2011).

Ezzell, G. A., Burmeister, J. W., Dogan, N., Losasso, T. J, Mechalakos, J. G., Mihailidis, D., Molineu, A., Palta, J. R., Ramsey, C. R., Salter, B. J., Shi, J., Xia, P., Yue, N. J., Xiao, Y. IMRT commissioning: Multiple institution planning and dosimetry comparisons, a report from AAPM Task Group 119. Med Phys 36, 5359-5373 (2009).

Feygelman, V., Stambaugh, C., Zhang, G., Hunt, D., Opp, D., Wolf, T. K., Nelms, B. E. Motion as a perturbation: Measurement guided dose estimates to moving patient voxels during modulated arc deliveries. Med Phys 40, 021708 (2013).

Fogarty G. B., D. Ng, G. Liu, L. E. Haydu, and N. Bhandari, "Volumetric modulated arc therapy is superior to conventional intensity modulated radiotherapy-a comparison among prostate cancer patients treated in an Australian centre," Radiation Oncology, vol. 6, no. 1, article 108, (2011).

Hall W. A., L. Colbert, D. Nickleach et al., "Reduced acute toxicity associated with the use of volumetric modulated arc therapy for the treatment of adenocarcinoma of the prostate," Practical Radiation Oncology, vol. 3, no. 4, pp. e157-e164, (2013). 
Kruse, J. J. On the insensitivity of single field planar dosimetry to IMRT inaccuracies. Med Phys 37, 2516-2524 (2010).

Lawrence, M., Wang, S., Cullip, T., Chang, S. Current IMRT QA metrics are not correlated with clinically relevant dosimetric errors in prostate and head neck treatments. Med Phys 38, 3816 (2011).

Low, D. A., Harms, W. B., Mutic, S., Purdy, J. A. A technique for the quantitative evaluation of dose distributions. Med Phys 25, 656-661 (1998).

Nelms B. E., H. Zhen, and W. A. Tomé, "Per-beam, planar IMRT QA passing rates do not predict clinically relevant patient dose errors," Med. Phys. 38(2), 1037-1044 (2011).

Prescribing, Recording, and Reporting Intensity-Modulated Photon-Beam Therapy (IMRT), ICRU Report No. 83, Journal of the ICRU, Vol. 10(1), Oxford, 2010.

Rowshanfarzad P., M. Sabet, M. Barnes, D. OConnor, and P. Greer, "EPID-based verification of the MLC performance for dynamic IMRT and VMAT," Med. Phys. 39, 6192-6205 (2012).

Taweap Sanghangthum, SivaleeSuriyapee, SomyotSrisatit and Todd Pawlicki; Statistical process control analysis for patient-specific IMRT and VMAT QA; Journal of Radiation Research, 54, 546-552, (2013).

Xing L, Li JG, Pugachev A, Le QT, Boyer AL. Estimation theoryand model parameter selectrion for therapeutic treatmentplan optimization. Med Phys; 26:2348-59, (1999).

Zelefsky MJ, Pei X, Teslova T, Secondary cancers after intensity-modulated radiotherapy, brachytherapy and radical prostatectomy for the treatment of prostate cancer: incidence and cause-specific survival outcomes according to the initial treatment intervention. BJU Intr., 110, 1696-701, (2012).

Zhen, H., Nelms, B. E., Tomé, W. A. Moving from Gamma passing rates to patient DVH based QA metrics in pretreatment dose QA. Med Phys 38, 5477-5489 (2011). 
الملخص باللغة العربية

\section{المقارنة بين معاملالتحليلالجامى و التوزيعالبياني الحجى للجرعة للعلاج الاشعاعلمرضى الاورام متغير الكثافة او

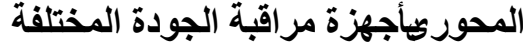

$$
\begin{aligned}
& \text { 1" ياسر حسن على ، 2. د.م/ خالد محمد الثحات3, ا.د./ حسنيةمحمدابوزيـد، 4. ا.د./ هدى عبد المنعم عشرى }
\end{aligned}
$$

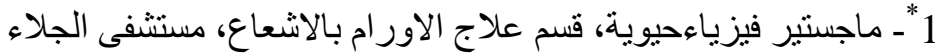

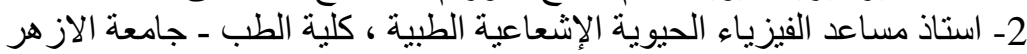

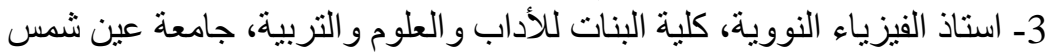

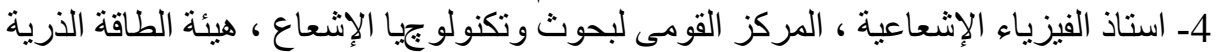

يعتبر التحقق من جودة الخريطة العلاجية للأور ام المحسوبة بأجهزة التخطيط ثلاثى الأبعاد الحديثةبإختلاف أنو اعها سو اء التقليدية او متغيرة الكثافة او المحورية أثناء العلاج ثم مقارنتها بتوزيع الجر عات العلاجية المقاسة فعليا بأجهزة مر اقبة الجودة المختلفة فى غرفة العلاج الإشعاعى وقبل تطبيق الخريطة العلاجية يعتبر من أهم الطرق لضمان علاج إثعاعى منميز يضمن أعلى توزيع للجر عة للورم السرطانى وضمان أقل جر عة ممكنه للأنسجة الحساسة المحيطة بالورم. فى هذا الصدد، يتم التحقق من جودة الخريطة العلاجية قبل علاج المريض عن طريق المقارنة بين توزيع الجرعة المحسوبة بجهاز التخطيط مع توزيع الجر عة المقاسة فعليا داخل الثبح المحاكى لجسم الإنسانو تعتبر طريقة تحليل معامل الجودة الجامى هى الأداة الأمنل لتحقيق المقارنة بين توزيع الجرعة المحسوبة بجهاز التخطيط وتوزيع الجرعة المقاسة فعليا عن طريق مقارنة قر اءة كل نقطة فى مصفوفة غرف التأين المقاسة بالنقطة المقابلة لها فى المصفوفة المحسوبة للخريطة العلاجية من حيث نسبة فرق الجر عة و تو افق حيز المسافة المحبطة .

وكان الهدف من العمل هو مقارنة التخطيط ثناثى الأبعاد بإختلاف أنو اعه سواء التقليد ى او متغير الكثافة او المحور ى أثناء علاج حالات أور ام الر أس و الرقبة ( عشرون مريض) لإختيار الأنسب للعلاج ثم تقيم الأنظمة المختلفة الحديثة لمر اقبة الجودة لأجززة العلاج الاشعاعى متغير الكثافة ودر اسة العلاقة بين توزيع الجرعة للتخطيط العلاجى ومعامل التحليل الجامى فى نظام مر اقبة الجودة للعلاج الاشعاعى متغير الكثافةو كذلك دراسة العلاقة بين توزيع الجر عة المقاسةتلارسمالبياني الحجمى للأعضاء الحساسة المختلفة ومعامل التحليل الجامى وقدرته على إكتثاف أخطاءالجر عاقفيالمرضى.

هذا وتعتبر أجهزة العلاج الاشعاعى متغير الكثافة للعلاج عن بعد من أهم النظم التى تحقق ذلك عن طريق الحركة المستمرة للمحددات متعددة الوريقات داخل الحقل الاشعاعى الو احد مع الحركة المستمرة لز اوية الر أس العلاجى أثناء نوجيه الحزمة الإشعاعية العلاجية . بما يضمن تدرج و تغير فى كثافة وتوزيع الجرعة الإشعاعية داخل الحقل الإشعاعى الو احد لكل زاوية من زوايا الر أس العلاجى ـ بما يضمن أعلى و أفضل توزيع للجرعة . هذهالدر استتقربأنمعامل التحليل الجامى فى نظام مر اقبة

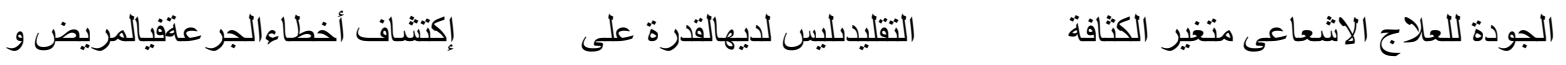

لضمانجودةمر اقبةالجر عتيجبأنيتضمن نظام مر اقبة الجودة على خاصية نوزيع الجر عة المقاسةتللرسمالبياني الحجمى للأعضاء الحساسة المختلفةأثناءالعلاج.و على ذللى، تعتبر الدراسة محاولة للتحقق من تغير توزيع الجرعة الناتج عن المحددات متعددة 
الوريقات داخل الحقل الاشعاعى مع الــزوايا العلاجية المختلفة وتأثثير ذلك على دقة أنظمة مر اقبة الجودة و تقيم الأداء للعلاج الإشعاعى متغير الكثافة قبل العلاج للمرضى . 